\title{
Halogen bonding in mono- and dihydrated halobenzene
}

Simon W.L. Hogan and Tanja van Mourik

EaStCHEM School of Chemistry, University of St Andrews, North Haugh, St Andrews, Scotland, United Kingdom

\begin{abstract}
Density functional theory calculations were performed on halogen-bonded and hydrogenbonded systems consisting of a halobenzene (XPh; $X=F, C l, B r, I, A t)$ and one or two water molecules, using the M06-2X density functional with the 6-31+G(d) (for $C, H, F, C l, B r$ ) and aug-cc-pVDZ-PP (for I, At) basis sets. The counterpoise procedure was performed to counteract the effect of basis set superposition error. The results show halogen bonds form in the $\mathrm{XPh}-\mathrm{H}_{2} \mathrm{O}$ system when $\mathrm{X}>\mathrm{Cl}$. There is a trend towards stronger halogen bonding as the halogen group is descended, as assessed by interaction energy and $\mathrm{X} \bullet \bullet \bullet \mathrm{O}_{\mathrm{w}}$ internuclear separation (where $\mathrm{O}_{w}$ is the water oxygen). For all XPh- $\mathrm{H}_{2} \mathrm{O}$ systems hydrogen-bonded systems exist, containing a combination of $\mathrm{CH} \bullet \bullet \bullet \mathrm{O}_{\mathrm{w}}$ and $\mathrm{O}_{\mathrm{w}} \mathrm{H}_{\mathrm{w}} \bullet \bullet \times \mathrm{X}$ hydrogen bonds. For all systems except $X=A$ t the $X \bullet \bullet \bullet H_{w}$ hydrogen-bonding interaction is stronger than the $X \bullet \bullet \bullet O_{w}$ halogen bond. In the XPh- $\left(\mathrm{H}_{2} \mathrm{O}\right)_{2}$ system halogen bonds form only for $\mathrm{X}>\mathrm{Br}$. The two water molecules prefer to form a water dimer, either located around the $\mathrm{C}-\mathrm{H}$ bond (for $\mathrm{X}=\mathrm{Br}, \mathrm{At}$, and I) or located above the benzene ring (for all halogens). Thus, even in the absence of competing strong interactions, halogen bonds may not form for the lighter halogens due to (i) competition from cooperative weak interactions such as $\mathrm{C}-\mathrm{H} \bullet \bullet \bullet \mathrm{O}$ and $\mathrm{OH} \bullet \bullet \times \mathrm{X}$ hydrogen bonds, or (ii) if the formation of the halogen bond would preclude the formation of a water dimer.
\end{abstract}

Keywords: Halogen bond, hydrogen bond, halobenzene, density functional theory, M06-2X 


\section{Introduction}

Non-covalent interactions such as hydrogen bonds ( $\mathrm{H}$-bonds) and $\pi-\pi$ interactions are known to play important roles in varying fields in chemistry and physics and, in particular, in biological disciplines. ${ }^{[1]}$ The attraction in non-covalent interactions originates from electrostatic, induction and dispersion contributions, whereas exchange-repulsion prevents the subsystems of approaching too closely. The attraction in hydrogen bonds is usually dominated by the electrostatic interaction with non-negligible contributions from induction and dispersion, ${ }^{[2,3]}$ whereas $\pi-\pi$ interactions are dominated by the dispersion contribution. Compared to hydrogen bonds, dispersion-dominated interactions were initially thought to be of smaller importance in determining the structure of biomolecules. However, it emerged over the last few decades that dispersion-dominated interactions can be of similar magnitude to hydrogen bonds and play important roles in shaping biomolecules. ${ }^{[4]}$ For example, stacking was found to be more important than hydrogen bonding in stabilising DNA. ${ }^{[5-7]}$ Dispersion interactions pose challenges to quantum-chemical methods, with methods like Hartree-Fock and many density functionals unable to describe this energy contribution. The emerging appreciation of the importance of dispersion interactions went hand-in-hand with the growing viability of using more accurate quantum-chemical methods (post-Hartree-Fock methods combined with larger basis sets), which recover more of the dispersion energy. The realisation of the importance of dispersion interactions has also driven the development of dispersion-corrected density functional theory ${ }^{[8]}$ and the development of multi-parameter functionals that are capable of describing dispersion. Of the latter, the M06-2X functional ${ }^{[9]}$ is probably the most accurate, giving good results for the S22 benchmark set as well as stacked structures, ${ }^{[10]}$ and was found to give broad accuracy for thermochemistry, kinetics, and noncovalent interactions. ${ }^{[11]}$

Another type of non-covalent interaction is the halogen bond (X-bond). Halogen bonds are similar to hydrogen bonds, but with a halogen atom taking the role of the hydrogen. Halogen bonds are a relatively new concept. Though the first halogen-bonded system, the complex formed between ammonia and iodine, ${ }^{[12]}$ was synthesised already in 1814, the term "halogen bond" was only first coined in 1987. ${ }^{[13]}$ Like dispersion, halogen bonds are generally weaker than hydrogen bonds, but they can in some circumstances be of similar or even greater magnitude than hydrogen bonds. ${ }^{[14,15]}$ Halogen bonds are in a similar situation now as dispersion-dominated interactions were two decades ago: the important role of halogen bonds in varying fields such as biomolecular structure and recognition has only just started to emerge. Research on halogen-bonded systems has increased massively in the last decade and the first review articles and perspectives have now started to appear in the literature. ${ }^{[16-20]}$ However, some aspects of halogen bonds are not yet fully explored. Whereas competition with other inter- or intramolecular interactions, such as hydrogen and chalcogen bonds and $\mathrm{C}-\mathrm{H} \bullet \bullet \bullet \pi$ and lone-pair $\bullet \bullet \pi$ interactions, has been the subject of numerous studies, ${ }^{[15,21-30]}$ in the current study we focus on an aromatic system with no functional groups besides the 
halogen (halobenzene; see below). Systematic studies on varying halogen-bonded systems may help to increase our knowledge of this fascinating type of non-covalent interaction.

Halogens are generally considered as sites of high electron density and it thus seems counterintuitive that they may interact with electron-rich sites (nucleophiles). Such interactions occur because, when the halogen is covalently bonded to another atom ( $\mathrm{Y}$ ), the electron density of the halogen is anisotropic: there is a negatively-charged "belt" orthogonal to the covalent bond and a (usually positive) site of low electron density, referred to as the $\sigma$ hole, at the elongation of this bond (though the overall charge on the halogen remains negative). In halogen bonds, nucleophiles interact with this the $\sigma$-hole. Because of the anisotropy in the electron distribution around the halogen, halogens can interact both with nucleophiles, when approaching the covalent bond head-on (where they see the $\sigma$-hole) as well as with electrophiles, when approaching the halogen at (near-)right angles (where they see the negative belt). ${ }^{[20,31]}$ Because the $\sigma$-hole is located along the extension of the $\mathrm{Y}$ - $\mathrm{X}$ bond, halogen bonds are highly directional with halogen-bond angles typically very close to $180^{\circ}$. However, it has been shown that significantly non-linear halogen bonds (with halogen-bond angles $150-160^{\circ}$ ) can occur, particularly in complex environments with competing interactions. ${ }^{[26,32]}$ The strength of halogen bonds is usually found to increase as the halogen group is descended. ${ }^{[32]}$ Fluorine generally does not form halogen bonds. ${ }^{[33]}$ This has been ascribed to the element's large electronegativity and its tendency to engage in $\mathrm{sp}$ hybridisation. These attributes produce an influx of negative charge into the region where the positive $\sigma$-hole would be. ${ }^{[18,34]}$

Recently, we studied the competition between hydrogen- and halogen-bonding interactions in complexes of 5-halogenated 1-methyluracil $(\mathrm{XmU})$ with one or two water molecules. ${ }^{[26,35]}$ In particular, we focussed on the competition between $\mathrm{X} \bullet \bullet \bullet$ halogen bonding and $O 4 \bullet \bullet \bullet \mathrm{H}_{\mathrm{w}}$ hydrogen bonding. Figure 1 shows the $\mathrm{H}$-bonded and $\mathrm{X}$-bonded $\mathrm{XmU}-\mathrm{H}_{2} \mathrm{O}$ and $\mathrm{XmU}-\left(\mathrm{H}_{2} \mathrm{O}\right)_{2}$ structures. In the singly-hydrated complexes, the water forms a halogen bond with $\mathrm{C} 5-\mathrm{X}$ only for halogens heavier than $\mathrm{Cl}$. However, doubly-hydrated halogen-bonded complexes, where the two waters form a bridge between $\mathrm{C} 4=\mathrm{O}$ and $\mathrm{C} 5-\mathrm{X}$, exist for all halogens heavier than $\mathrm{F}$ (including $\mathrm{Cl}$ ). Thus, the absence of a halogen bond in singly-hydrated $\mathrm{ClmU}$ can be attributed to the competing interaction of the water molecule with the $\mathrm{C} 4=\mathrm{O}$ moiety. 


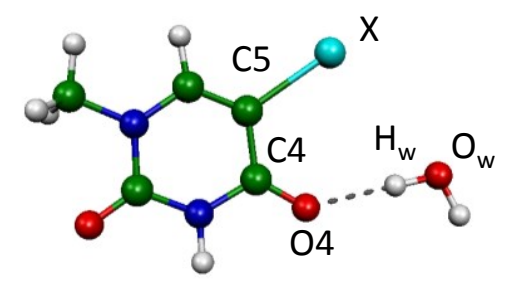

H-bonded $\mathrm{XmU}-\mathrm{H}_{2} \mathrm{O}$

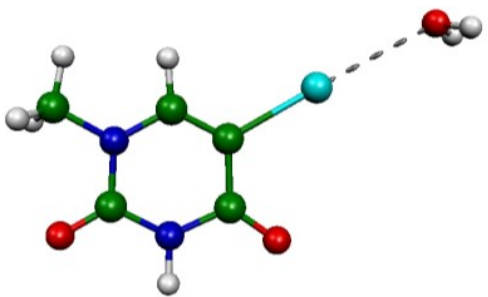

X-bonded $\mathrm{XmU}-\mathrm{H}_{2} \mathrm{O}$

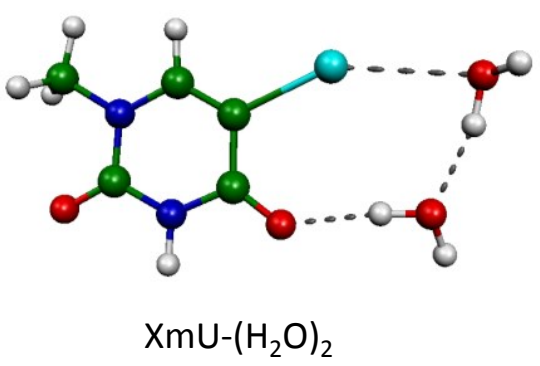

Figure 1. The structures of $\mathrm{H}$-bonded and $\mathrm{X}$-bonded $\mathrm{XmU}-\mathrm{H}_{2} \mathrm{O}$ and $\mathrm{XmU}-\left(\mathrm{H}_{2} \mathrm{O}\right)_{2}$

In the current paper we focus on halogen bonding between halobenzene (XPh) and one or two water molecules. The $\mathrm{XPh}-\mathrm{H}_{2} \mathrm{O}$ complex can be considered a simpler analogue of $\mathrm{XmU}$ $\mathrm{H}_{2} \mathrm{O}$. As the $\mathrm{C} 4=\mathrm{O}$ moiety is missing in $\mathrm{XPh}-\mathrm{H}_{2} \mathrm{O}$, the system serves as a model for $\mathrm{XmU}-\mathrm{H}_{2} \mathrm{O}$ lacking the opportunity for $\mathrm{O} 4 \bullet \bullet \mathrm{H}_{\mathrm{w}}$ hydrogen bonding. However, H-bonding type interactions can still occur in the $\mathrm{XPh}-\mathrm{H}_{2} \mathrm{O}$ systems, with the negatively charged ring on the halogen atom acting as the electron donor, i.e. $\mathrm{X} \bullet \bullet \bullet \mathrm{H}_{\mathrm{w}}$ interaction. In addition to serving as a useful comparator for the more elaborate $\mathrm{XmU}-\mathrm{H}_{2} \mathrm{O}$ system, this study aims to cast further light upon the halogen-bonding attributes of halobenzene where the nucleophile is water, including for the under-studied halogen-bonding properties of astatine. While astatine may not be biologically relevant, including this halogen in studies on halogen bonds may help to reveal trends in energy and properties with increasing halogen size, particularly in cases where the chlorine- and bromine-containing systems do not form halogen bonds.

Several studies on halogen bonding involving halobenzenes are available in the literature. Adasme-Carreno et al. ${ }^{[36]}$ studied substituent effects in halogenated benzene complexed with $\mathrm{N}$-methylacetamide. A strong correlation was found between interaction energies and a set of attributes that reflect electrostatic properties, specifically, natural bond orbital charges, molecular electrostatic plots and electron density. The effect of the substituent upon the halogen bond was found to be due to the electrostatics of the system rather than resonance effects. A combined experimental (resonant two-photon ionisation spectroscopy) and computational study on homoclusters of chlorobenzene did not find evidence of halogen bonding. ${ }^{[37]}$ The authors argue that the lack of electron-withdawing substituents on the phenyl moiety reduces the size of the $\sigma$-hole, with the result that other interactions $(\pi \bullet \bullet \bullet \pi$ and $\mathrm{CH} \bullet \bullet \pi$ ) are dominant. A subsequent study on bromobenzene dimer identified several halogen-bonded bromobenzene dimer complexes, including two halogen $\bullet \bullet \pi$ interactions and one side-on interaction of the two bromine atoms, with energies ranging from 5.6 to 9.5 
$\mathrm{kJ} / \mathrm{mol} .{ }^{[38]}$ However, an experimental study using ${ }^{13} \mathrm{C}$ nuclear magnetic resonance spectroscopy on binary mixtures of $\mathrm{C}_{6} \mathrm{D}_{6}$ with $\mathrm{C}_{6} \mathrm{~F}_{5} \mathrm{X}(\mathrm{X}=\mathrm{Cl}, \mathrm{Br}, \mathrm{I})$ found $\mathrm{C}-\mathrm{X} \bullet \bullet \bullet \pi$ halogen bonds only for $X=1 .{ }^{[39]}$ Sutradhar and Chandra studied halogen bonding in complexes consisting of substituted chlorobenzene and trimethylamine. ${ }^{[40]}$ Symmetry-adapted perturbation theory (SAPT) calculations suggest that both electrostatic as well as dispersion interactions are present in these systems. Gresh et al. studied the double-faceted nature of the $\mathrm{C}-\mathrm{X}$ bond $(\mathrm{X}=\mathrm{Cl}, \mathrm{Br}) \cdot{ }^{\left[{ }^{[1,42]}\right.}$ They found that both features (electron-deficiency along the $\mathrm{C}-\mathrm{X}$ direction and electron-rich belt) can be enhanced by appropriate electron-withdrawing or electrondonating substituents.

\section{Methodology}

Structures comprising one halobenzene molecule and one or two water molecule $\left(X \mathrm{Ph}-\mathrm{H}_{2} \mathrm{O}\right.$ and XPh- $\left(\mathrm{H}_{2} \mathrm{O}\right)_{2}$ ) were created using Gaussview 4.1. ${ }^{[43]}$ Each halobenzene molecule contains one halogen atom substituting for a hydrogen atom on the benzene molecule; $\mathrm{X}=\mathrm{F}, \mathrm{Cl}, \mathrm{Br}, \mathrm{I}$ or At. Two minima of particular interest were sought: one forming a $\mathrm{C}-\mathrm{X} \bullet \bullet \mathrm{O}_{\mathrm{w}}$ halogen bond, and one with a $\mathrm{C}-\mathrm{X} \bullet \bullet \mathrm{H}_{\mathrm{w}}$ hydrogen bond. All calculations were performed with the M06-2X meta-hybrid functional, ${ }^{[44]}$ using Gaussian 09. ${ }^{[45]}$ For iodine and astatine the aug-cc-pVDZ-PP basis with corresponding relativistic effective core potential ${ }^{[46]}$ was employed, whereas all other atoms employed the $6-31+G(d)$ basis set. This level of theory was chosen to facilitate comparison with our previous work on $\mathrm{XmU}-\mathrm{H}_{2} \mathrm{O}$ and $\mathrm{XmU}-\left(\mathrm{H}_{2} \mathrm{O}\right)_{2}{ }^{[26,35]}$ In addition, the M06$2 X$ functional was found to be one of the best functionals for dissociation energies and geometries of X-bonded dimers. ${ }^{[47]}$ Ref. ${ }^{[47]}$ used two $\operatorname{CCSD}(T)$ benchmark sets: a moderate set of 18 small dimers (XB18) for the geometries and a large set of 51 dimers (XB51), which contains a broad range of association energies, for the energies. M06-2X is also capable of capturing dispersion, which is an important component of halogen bonds; ${ }^{[19]}$ in fact, in a previous study on stacked uracil dimer, a comparison of the gas-phase M06-2X/6-31+G(d) interaction energies with estimated $\operatorname{CCSD}(\mathrm{T}) / \mathrm{CBS}$ (complete basis set) values showed the excellent performance of this functional/basis set combination for stacking energies (which are heavily dispersion-dominated). ${ }^{[48]}$

Full geometry optimisations were performed using Gaussian's tight convergence criteria. The monohydrated systems invoked the counterpoise correction procedure (CP) proposed by Boys and Bernardi ${ }^{[49]}$ during the geometry optimisation, whereas the dihydrated systems were optimised on the uncorrected potential energy surface. Not including counterpoise in the optimisation was checked to have only a very minor effect on the interaction energy $(0.3$ $\mathrm{kJ} / \mathrm{mol}$ for IPh- $\left.\left(\mathrm{H}_{2} \mathrm{O}\right)_{2}\right)$. CP-corrected energies were obtained by subtracting the energies of the optimised monomers (halobenzene and one or two waters) from the CP-corrected dimer energy. All calculations used Gaussian's "ultrafine" integration grid, as meta-functionals may yield spurious results when course or default integration grids are employed. ${ }^{[50,51]}$ 
Gaussian uses by default five (spherical harmonic) d-functions when using the "GEN" keyword (which is required when specifying different basis sets for different atoms, as in the calculations including iodine or astatine), whereas otherwise it uses six (Cartesian) $d$-functions when employing the $6-31+G(d)$ basis set. As the $\mathrm{CP}$-corrected energies are computed by subtracting the energies of the isolated optimised monomers ( $\mathrm{XPh}$ and $\mathrm{H}_{2} \mathrm{O}$ ) from the CPcorrected dimer energy of the complex $\left(\mathrm{XPh}-\mathrm{H}_{2} \mathrm{O}\right.$ and XPh- $\left.\left(\mathrm{H}_{2} \mathrm{O}\right)_{2}\right)$, one needs to ensure the same basis sets are used in all calculations involved in the calculation of the interaction energy. ${ }^{[35]}$ For systems involving I and At, we therefore used five $d$-functions for the geometry optimisation of isolated water.

Wiberg Bond Indices ${ }^{[52]}$ were calculated by specifying a natural bond orbital population analysis by including the keyword "pop=nboread", and further providing a stand-alone directive at the end of the input file "\$NBO BNDIDX \$END". The Wiberg Bond Index between each pair of atoms was then computed by Gaussian 09.

Cartesian coordinates of all optimized minima and transition can be found in the Supporting Information.

\section{Results and discussion}

\section{$\mathrm{XPh}-\mathrm{H}_{2} \mathrm{O}$ results}

Figure 2 shows molecular electrostatic potential (MEP) maps for the XPh molecules. As is usually observed, ${ }^{[14,17,18,22,23,32,34,53-58]}$ FPh does not exhibit a $\sigma$-hole, consistent with the general observation that fluorine does not engage in halogen bonds. For CIPh, though the anisotropy of the electron density around the halogen atom is apparent from the MEP plot, the effect of this anisotropy is to produce an approximately neutral region (indicated by the green region) at the extension of the $\mathrm{C}-\mathrm{Cl}$ bond. As expected, given the electronegativity of chlorine, the total charge around the chlorine atom is negative. The molecules containing the heavier halogens all clearly show a $\sigma$-hole at the extension of the $\mathrm{C}-\mathrm{X}$ bond (blue regions). As usually observed, the $\sigma$-hole increases with increasing size of the halogen. The rim of negative charge around the halogens (red ring in the MEP plots) indicates that these can act as hydrogen-bond acceptors with electrophiles approaching side-on.

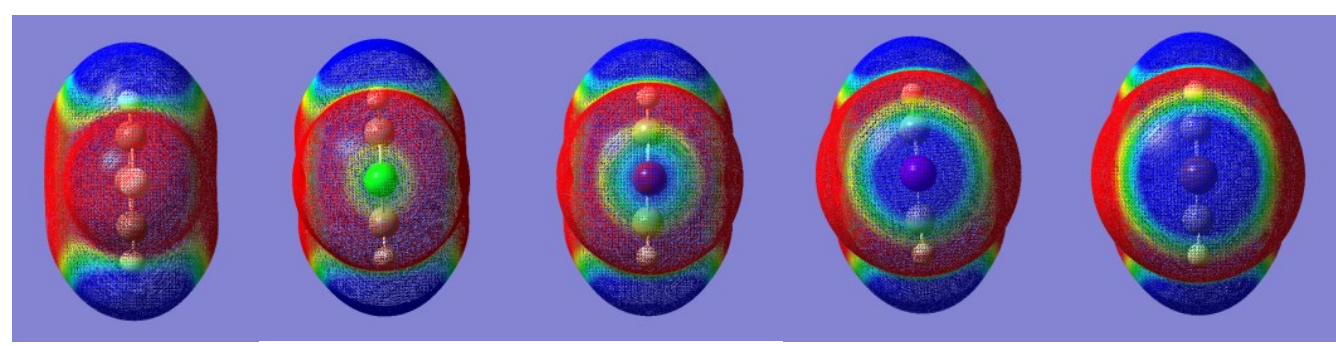

Figure 2. Molecular electrostatic potential maps (mapped on the $0.0004 \mathrm{e}^{-} / \mathrm{au}^{3}$ electron density surface) for the $\mathrm{XPh}(\mathrm{X}=\mathrm{F}, \mathrm{Cl}, \mathrm{Br}, \mathrm{I}, \mathrm{At})$ molecules. Blue and red represent positive and negative regions of electrostatic potential, respectively (from 6.93E-3 to $-6.93 \mathrm{E}-3 \mathrm{Eh} / \mathrm{e}^{-}$). 
The $\mathrm{H}$-bonded and $\mathrm{X}$-bonded minima located are displayed in Figure 3, whereas Tables 1 and 2 list the interaction energies and relevant geometric parameters, respectively. For all types of halogen atom, a H-bonded minimum was located. However X-bonded minima were only found for $\mathrm{X}=\mathrm{Br}$, I or At. The interaction energy of the $\mathrm{X}$-bonded structures becomes more negative (attractive) going down the halogen group from bromine to astatine. Figure 4 shows that the increase in interaction energy is very nearly linear. This near-linearity was also observed for $m X U-\mathrm{H}_{2} \mathrm{O}(\mathrm{X}=\mathrm{Br}, \mathrm{I}, \mathrm{At})$ and $\mathrm{mXU}-\left(\mathrm{H}_{2} \mathrm{O}\right)_{2}(\mathrm{X}=\mathrm{Cl}, \mathrm{Br}, \mathrm{I}, \mathrm{At}){ }^{[26,35]}$ The fluorinated structure clearly forms the strongest $\mathrm{H}$-bond with the shortest $\mathrm{X} \bullet \bullet \bullet \mathrm{H}_{\mathrm{w}}$ distance, in agreement with an analysis of the Cambridge Structural Database (CSD), which showed that C(aromatic)$\mathrm{F} \bullet \bullet \bullet \mathrm{H}$ distances show a well-defined minimum, but corresponding $\mathrm{Cl} \bullet \bullet \bullet \mathrm{H}$ and $\mathrm{Br} \bullet \bullet \mathrm{H}$ distances in the CSD do not have a maximum below the sum of the van der Waals distances of $\mathrm{H}$ and the halogen. ${ }^{[59]}$ The interaction energies of the other $\mathrm{H}$-bonded $\mathrm{XPh}-\mathrm{H}_{2} \mathrm{O}$ structures do not show a clear trend and are within $5 \mathrm{~kJ} / \mathrm{mol}$ of each other. The non-hydrogen-bonding water hydrogen is slightly out of plane for $\mathrm{X}=\mathrm{F}$ to $\mathrm{I}$, with an out-of-plane angle (calculated as the angle between the water $\mathrm{OH}$ bond and the plane of the halobenzene ring) $<20^{\circ}$. The outof-plane angle is largest $\left(54^{\circ}\right)$ for $\mathrm{X}=$ At. Similar geometries with out-of-plane water hydrogens were also observed for uracil- $\left(\mathrm{H}_{2} \mathrm{O}\right)_{n}(n=1-4)$ clusters. $^{[60]}$ 

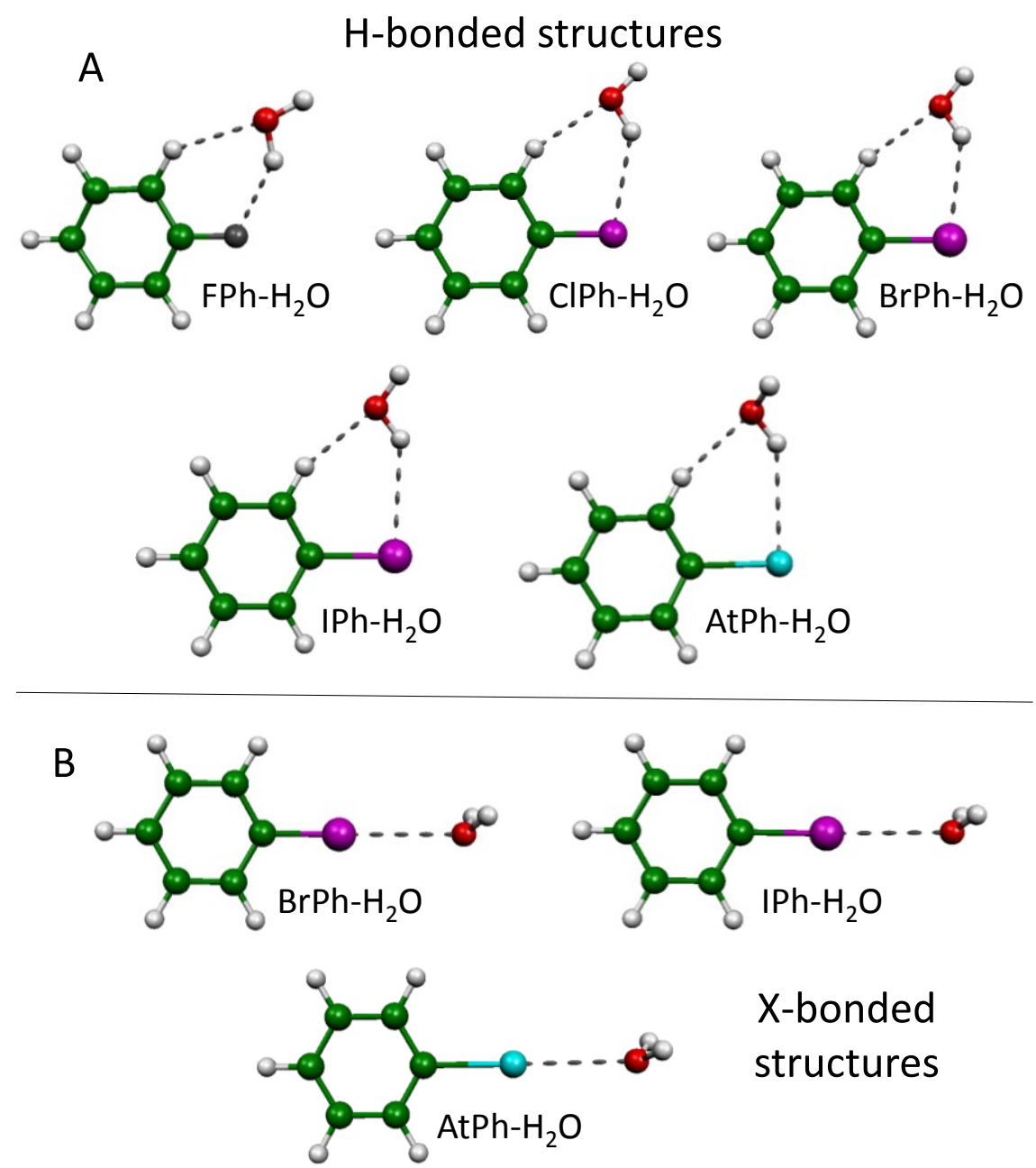

Figure 3. $\mathrm{H}$-bonded (A) and X-bonded (B) minimum-energy structures of XPh- $\mathrm{H}_{2} \mathrm{O}$

Table 1. Interaction energies (in $\mathrm{kJ} \mathrm{mol}^{-1}$ ) for the $\mathrm{H}$-bonded and $\mathrm{X}$-bonded geometries of $\mathrm{XPh}$ $\mathrm{H}_{2} \mathrm{O}$.

\begin{tabular}{lrrrrr}
\hline Structure & $\mathrm{X}=\mathrm{F}$ & $\mathrm{X}=\mathrm{Cl}$ & $\mathrm{X}=\mathrm{Br}$ & $\mathrm{X}=\mathrm{I}$ & $\mathrm{X}=\mathrm{At}$ \\
\hline $\mathrm{X}$-bonded & $\mathrm{n} / \mathrm{a}$ & $\mathrm{n} / \mathrm{a}$ & -7.3 & -13.3 & -18.6 \\
H-bonded & -16.5 & -14.2 & -14.5 & -14.6 & -14.1 \\
\hline
\end{tabular}

For $\mathrm{X}=\mathrm{Br}$ the $\mathrm{X}$-bonded structure is approximately half as stable as the $\mathrm{H}$-bonded structure (with an interaction energy difference of $7.2 \mathrm{~kJ} \mathrm{~mol}^{-1}$ ); for $X=1$ this difference has much diminished (to only $1.3 \mathrm{~kJ} \mathrm{~mol}^{-1}$ ), due to an increase in the X-bond interaction. This trend continues for $\mathrm{X}=\mathrm{At}$ in which the $\mathrm{X}$-bonded structure is more strongly stabilised than the $\mathrm{H}$ bonded by $4.5 \mathrm{~kJ} \mathrm{~mol}^{-1}$. Indeed, the AtPh- $\mathrm{H}_{2} \mathrm{O}$ X-bonded structure has a larger interaction energy than any of the $\mathrm{H}$-bonded structures. 
Table 2 shows the $\mathrm{H}$-bond or $\mathrm{X}$-bond distance and angle for each of the minima that were found for the $\mathrm{XPh}-\mathrm{H}_{2} \mathrm{O}$ systems. For the $\mathrm{H}$-bonded structures these are the $\mathrm{X} \bullet \bullet \bullet \mathrm{H}_{\mathrm{w}}$ distance and $\mathrm{C}-\mathrm{X} \bullet \bullet \mathrm{H}_{\mathrm{w}}$ angle (where $\mathrm{H}_{\mathrm{w}}$ is the hydrogen atom on the water molecule that is involved in hydrogen bonding), whereas for the $\mathrm{X}$-bonded structures these are the $\mathrm{X} \bullet \bullet \bullet \mathrm{O}_{\mathrm{w}}$ distance and $\mathrm{C}-\mathrm{X} \bullet \bullet \mathrm{O}_{\mathrm{w}}$ angle. Also shown are the $\mathrm{C}-\mathrm{H}$ or $\mathrm{C}-\mathrm{X}$ bond distances.

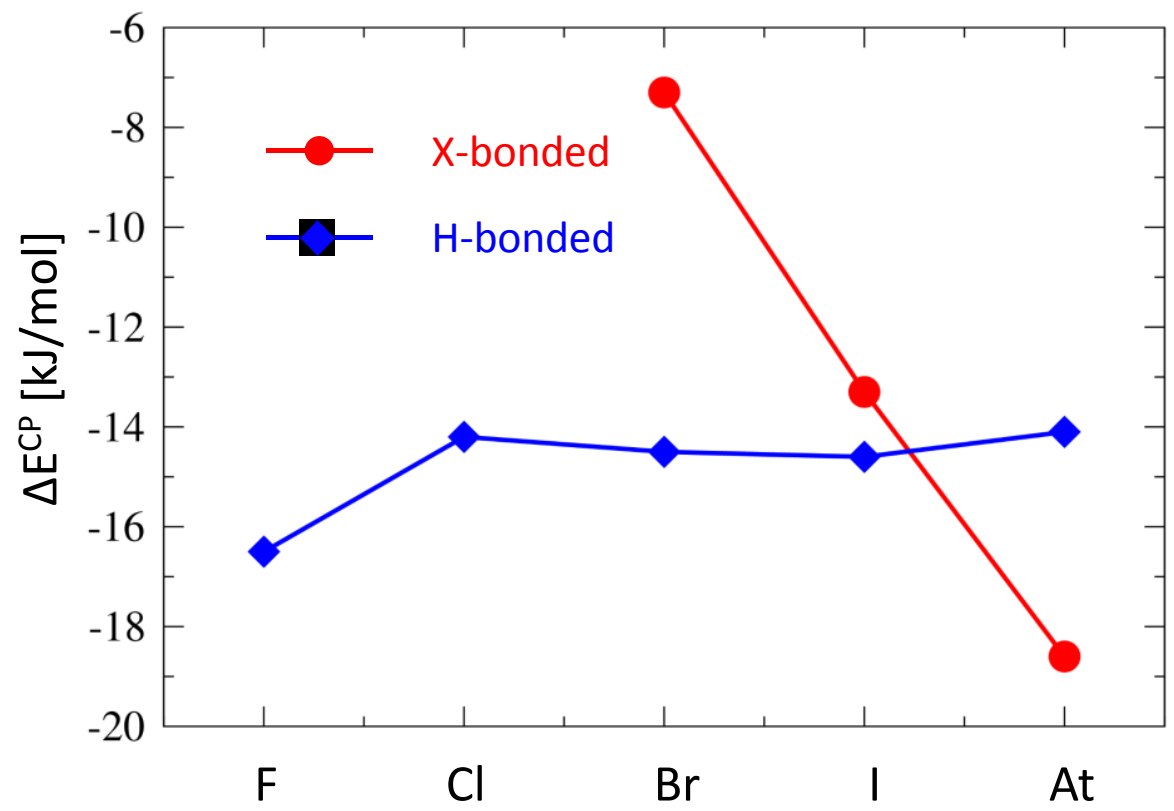

Figure 4. Interaction energies (in $\mathrm{kJ} / \mathrm{mol}$ ) for the $\mathrm{H}$-bonded and $\mathrm{X}$-bonded $\mathrm{XPh}-\mathrm{H}_{2} \mathrm{O}$ systems

Table 2. Geometric parameters (distances in $\AA$; angles in degrees) for the H-bonded and Xbonded geometries of $\mathrm{XPh}-\mathrm{H}_{2} \mathrm{O}$.

\begin{tabular}{|c|c|c|c|c|c|}
\hline Structure & $X=F$ & $\mathrm{X}=\mathrm{Cl}$ & $\mathrm{X}=\mathrm{Br}$ & $X=1$ & $X=A t$ \\
\hline \multicolumn{6}{|c|}{ Bond distance $\left(\mathrm{X} \bullet \bullet \mathrm{H}_{\mathrm{w}}\right.$ for $\mathrm{H}$-bonded and $\mathrm{X} \bullet \bullet \mathrm{O}_{\mathrm{w}}$ for $\mathrm{X}$-bonded structures $)$} \\
\hline X-bonded & $\mathrm{n} / \mathrm{a}$ & $\mathrm{n} / \mathrm{a}$ & 3.06 & 3.08 & 3.01 \\
\hline H-bonded & 2.05 & 2.59 & 2.70 & 2.89 & 2.96 \\
\hline \multicolumn{6}{|c|}{ Bond angle $\left(\mathrm{C}-\mathrm{X} \bullet \bullet \bullet \mathrm{H}_{\mathrm{w}}\right.$ for $\mathrm{H}$-bonded and $\mathrm{C}-\mathrm{X} \bullet \bullet \bullet \mathrm{O}_{\mathrm{w}}$ for $\mathrm{X}$-bonded structures $)$} \\
\hline X-bonded & $\mathrm{n} / \mathrm{a}$ & $\mathrm{n} / \mathrm{a}$ & 179 & 179 & 179 \\
\hline H-bonded & 117 & 101 & 97 & 92 & 89 \\
\hline \multicolumn{6}{|c|}{ C-H distance (C-X for X-bonded structures) } \\
\hline X-bonded & $\mathrm{n} / \mathrm{a}$ & $\mathrm{n} / \mathrm{a}$ & 1.88 & 2.11 & 2.21 \\
\hline H-bonded & 1.36 & 1.75 & 1.89 & 2.12 & 2.21 \\
\hline
\end{tabular}

Table 2 demonstrates a trend towards stronger halogen bonds as the halogen group is descended, with a decrease in internuclear separation from the iodinated to astatinated systems and only a very small $(0.02 \AA)$ increase from the brominated to the iodinated species. This can be demonstrated more clearly using van der Waals ratios, which are the internuclear 
distance divided by the sum of Van der Waals (VdW) radii ${ }^{[61,62]}$ for the halogen bonds. These are $0.91,0.88$ and 0.85 for the $X=B r, I$ and At systems, respectively. Thus, there is a consistent trend towards smaller $\mathrm{VdW}$ ratios from bromine to astatine. As smaller internuclear separations, and in particular smaller VdW ratios, are associated with stronger interatomic interactions, this trend towards shorter halogen bonds going down the halogen group further supports the energetic findings presented in Table 1 that halogen bonds become stronger as the identity of the halogen atom is varied going down the halogen group from bromine to astatine. By contrast, the $\mathrm{H}$-bond distances increase going down the halogen group for the $\mathrm{H}$ bonded structures.

The bond angles of the X-bonded structures are very close to linear $\left(179^{\circ}\right)$ in all cases. This result is to be expected as (i) the ideal angle for a halogen bond is linear due to the position of the $\sigma$ hole, which is situated trans with respect to the $C-X$ bond, ${ }^{[63]}$ and (ii) there are no significant secondary interactions. For the $\mathrm{H}$-bonded structures the $\mathrm{C}-\mathrm{X} \bullet \bullet \bullet \mathrm{H}_{\mathrm{w}}$ angle shows a clear trend in decreasing as the halogen group is descended. This can be explained as the electron density on the halogen atom is concentrated in the negatively charged belt that is approximately perpendicular to the $\mathrm{C}-\mathrm{X}$ bond axis. As the size of the $\sigma$-hole increases going down the group this relocation of electron density towards the perpendicular position would become more pronounced. The further that the electron density must be displaced from the linear region, the more it will concentrate in the perpendicular region, moving the location of maximum density to smaller angles. In the case of $\mathrm{AtPh}-\mathrm{H}_{2} \mathrm{O}$, a slightly acute angle $\left(89^{\circ}\right)$ is formed, suggesting that the peak in electron density, in this extreme case, is pushed back even slightly beyond perpendicular in order to accommodate the large $\sigma$-hole. However a greater factor might be that the $\mathrm{C}-\mathrm{X}$ bond distance increases down the halogen group (Table 2). Part of the reason for the greater $C-X$ bond distance will be due to donation into the $\sigma^{*}$ antibonding orbital, which corresponds to the $\sigma$-hole, but the principal contributor to increased C-X bond distance is presumably the increased Van der Waals radius of the halogen atom.

The Wiberg bond indices for the $\mathrm{X} \bullet \bullet \mathrm{O}_{\mathrm{w}}$ halogen bond in the $\mathrm{X}$-bonded $\mathrm{XPh}-\mathrm{H}_{2} \mathrm{O}(\mathrm{X}=\mathrm{Br}, \mathrm{I}, \mathrm{At})$ structures are $0.0098,0.0178$ and 0.0248 , respectively. Clearly, the indices increase with increasing size of halogen atom. The absolute values are low in comparison with other types of interaction. From these values it can be concluded that the oxygen-halogen interaction (i) has slight covalent character but is not predominantly covalent and (ii) the degree of covalency increases as the halogen group is descended. The trend of increasing Wiberg bond indices for the heavier halogens is consistent with the observations made above based upon energetic and geometric results, i.e. that the halogen bond strength increases going down the halogen group from $\mathrm{X}=\mathrm{Br}$ to $\mathrm{X}=\mathrm{At}$.

\section{XPh- $\left(\mathrm{H}_{2} \mathrm{O}\right)_{2}$ results}

In our previous work, ${ }^{[26,35]}$ we found that a single water molecule does not bind to chlorinated $\mathrm{XmU}$ though a halogen bond. Instead, the water molecule forms a hydrogen bond with the 
neighbouring $\mathrm{C} 4=\mathrm{O} 4$ moiety. This competing interaction is absent in $\mathrm{XPh}$. However, the single hydrated CIPh system does not form a halogen bond, either; the water molecule is located between $\mathrm{C}-\mathrm{Cl}$ and a neighbouring $\mathrm{C}-\mathrm{H}$ unit, forming two hydrogen bonds $\left(\mathrm{C}-\mathrm{H} \bullet \bullet \bullet \mathrm{O}_{\mathrm{w}}\right.$ and $\mathrm{C}$ $\mathrm{Cl} \bullet \bullet \mathrm{H}_{\mathrm{w}}$; see previous section). To see if we can similarly block the competing $\mathrm{C}-\mathrm{H}$ bond in $\mathrm{ClPh}$ and thus form a C-Cl $\bullet \bullet \mathrm{O}_{\mathrm{w}}$ halogen bond, we created $\mathrm{XPh}-\left(\mathrm{H}_{2} \mathrm{O}\right)_{2}$ starting structures for geometry optimisation, with one water molecule $\mathrm{H}$-bonded to $\mathrm{C}-\mathrm{H}$ and the other one $\mathrm{X}$ bonded to $\mathrm{C}-\mathrm{X}$. For $\mathrm{X}=\mathrm{I}$ and $\mathrm{At}$, the optimisations converged to structures with one water molecule $\mathrm{X}$-bonding to $\mathrm{C}-\mathrm{X}$ whereas the other one forms two $\mathrm{H}$-bonds: one $\mathrm{C}-\mathrm{H} \bullet \bullet \bullet \mathrm{O}_{\mathrm{w}}$ and one $\mathrm{O}_{\mathrm{w}}-\mathrm{H}_{\mathrm{w}} \bullet \bullet \mathrm{X}$ hydrogen bond (labelled "Type 1" in Figure 5). The $\mathrm{H}$-bonding water molecule is coplanar with the benzene ring, whereas the hydrogens of the X-bonding water molecule point to opposite sides of the benzene ring. The complex has thus $\mathrm{C}_{s}$ symmetry. $\mathrm{BrPh}-\left(\mathrm{H}_{2} \mathrm{O}\right)_{2}$ converged to a structure where a water dimer is located around the $\mathrm{C}-\mathrm{H}$ bond "Type 2 " in Figure 5). The oxygen of one of the water molecules is located between adjacent $\mathrm{C}-\mathrm{H}$ bonds, presumably forming two favourable bifurcated $\mathrm{C}-\mathrm{H} \bullet \bullet \mathrm{O}_{\mathrm{w}}$ contacts. The two hydrogens of the other water molecule point in the direction of the bromine, presumably interacting with the negative belt around the halogen. This complex type is also $\mathrm{C}_{\mathrm{s}}$-symmetric. Further investigation found similar structures for the iodinated and astatinated species as well. ClPh$\left(\mathrm{H}_{2} \mathrm{O}\right)_{2}$ converged to a structure with the water molecule located above the benzene ring ("Type 3" in Figure 5). Similar structures were also found for the other halogens. The strongest interaction in the Type 3 structures occurs for $X=B r$ (see Table 1 ). The brominated structure also has the shortest $X \bullet \bullet H_{w}$ contact: the $X \bullet \bullet H_{w}$ distances are 3.6, 3.5, 2.6, 3.5 and $3.6 \AA$, for $X=F, C l, B r, I$ and $A t$, respectively. For $F P h-\left(\mathrm{H}_{2} \mathrm{O}\right)_{2}$ we also found a structure with the water dimer located in the region between $\mathrm{C}-\mathrm{X}$ and $\mathrm{C}-\mathrm{H}$ (not shown). This form does not exist for the other halogens. Note that we were interested in structures where one water forms an $\mathrm{H}$ bond and the other one a X-bond; we therefore did not search for other structures besides Types 1-3, and Type 2 may not be the global minimum on the XPh- $\left(\mathrm{H}_{2} \mathrm{O}\right)_{2}$ surface.

Thus, even in the absence of the competing $\mathrm{C} 4=\mathrm{O} 4$ moiety, there are numerous other competing interactions preventing the formation of a $\mathrm{C}-\mathrm{Cl} \bullet \bullet \mathrm{O}_{\mathrm{w}}$ halogen bond. In singlyhydrated $\mathrm{ClPh}$ the presence of the neighbouring $\mathrm{C}-\mathrm{H}$ unit persuades the water molecule away from its $\mathrm{X}$-bonding position to form a structure with two unconventional $\mathrm{H}$-bonds $(\mathrm{a} \mathrm{CH} \bullet \bullet \bullet \mathrm{O}$ and $\mathrm{OH} \bullet \bullet \mathrm{Cl} \mathrm{H}$-bond), whereas in doubly-hydrated ClPh the two waters prefer to form a water dimer located above the aromatic ring. The propensity of forming a water dimer, at the expense of a halogen bond, is so strong that even $\mathrm{Br}$ cannot form a halogen bond in the doubly-hydrated complex. 
Type 1

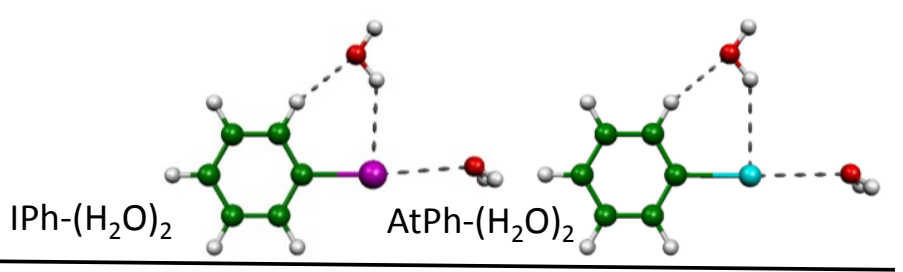

Type 2

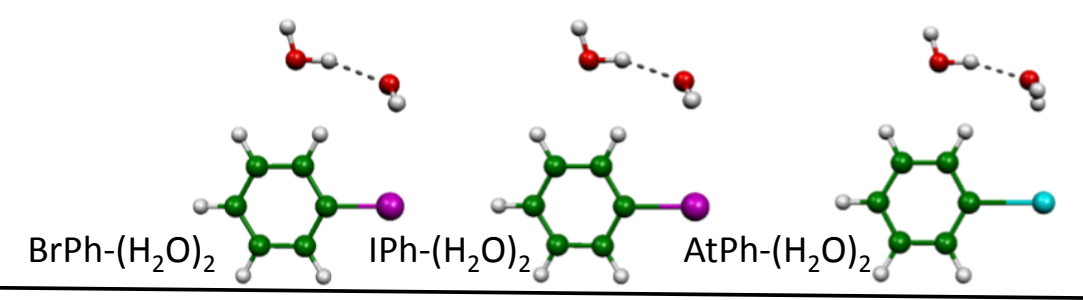

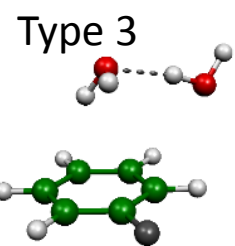

$\mathrm{FPh}-\left(\mathrm{H}_{2} \mathrm{O}\right)_{2}$

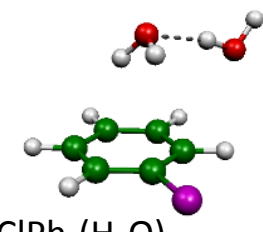

$\mathrm{ClPh}-\left(\mathrm{H}_{2} \mathrm{O}\right)_{2}$

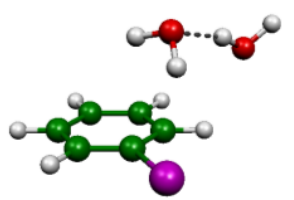

$\operatorname{BrPh}-\left(\mathrm{H}_{2} \mathrm{O}\right)_{2}$

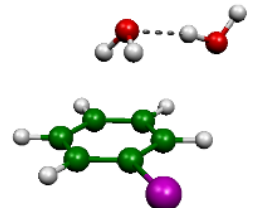

$\mathrm{IPh}-\left(\mathrm{H}_{2} \mathrm{O}\right)_{2}$

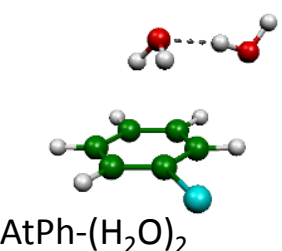

AtPh- $\left(\mathrm{H}_{2} \mathrm{O}\right)_{2}$

Figure 5. Different structures of $\mathrm{XPh}-\left(\mathrm{H}_{2} \mathrm{O}\right)_{2}$

The interaction energies of the XPh- $\left(\mathrm{H}_{2} \mathrm{O}\right)_{2}$ structures are shown in Table 3. Type 2 and Type 3 structures, which both contain a water-water $\mathrm{H}$-bond, are clearly more stable than the Type 1 structures.

Table 3. Interaction energies (in $\mathrm{kJ} \mathrm{mol}^{-1}$ ) for the different $\mathrm{XPh}-\left(\mathrm{H}_{2} \mathrm{O}\right)_{2}$ structures.

\begin{tabular}{llllll}
\hline Structure & $X=F$ & $X=C l$ & $X=B r$ & $X=1$ & $X=A t$ \\
\hline Type 1 & & & -29.69 & -33.50 \\
Type 2 & & & -49.55 & -47.52 & -46.98 \\
Type 3 & -51.20 & -52.20 & -55.91 & -53.16 & -53.43 \\
\hline
\end{tabular}

The Wiberg bond indices for the halogen bond in the Type 1 structures are 0.0192 and 0.0235 for $X=I$ and At, respectively i.e., similar in magnitude as for the singly-hydrates species. The bond indices of the $\mathrm{H}_{\mathrm{w}} \bullet \bullet \times \mathrm{X}$-bond are similar in magnitude $(0.0200$ and 0.0210 , respectively, whereas those of the $\left(\mathrm{C}-\mathrm{H} \cdot \bullet \bullet \mathrm{O}_{\mathrm{w}}\right.$ interaction are smaller $(0.0098$ and 0.0096 , respectively). To investigate cooperative effects, we computed the counterpoise-corrected interaction energies of the fragment consisting of XPh and the $\mathrm{H}$-bonded (or X-bonded) water interacting with the X-bonded (or H-bonded) water molecule (all at the optimised XPh- $\left(\mathrm{H}_{2} \mathrm{O}\right)_{2}$ geometry). The interaction energies for the (XPh $+\mathrm{X}$-bonded water) $\bullet \bullet \bullet(\mathrm{H}$-bonded water) complex are 16.6 and $-15.1 \mathrm{~kJ} / \mathrm{mol}$ for I and At, respectively, compared to -14.6 and $-14.1 \mathrm{~kJ} / \mathrm{mol}$ when the $\mathrm{X}$-bonded water is absent. Similarly, the interaction energies for the $\mathrm{XPh}+\mathrm{H}$-bonded water) $\bullet \bullet(X-$ bonded water) complex are -15.4 and $-19.7 \mathrm{~kJ} / \mathrm{mol}$ for I and At, respectively, compared to -13.3 and $-18.6 \mathrm{~kJ} / \mathrm{mol}$ when the $\mathrm{H}$-bonded water is absent. Thus, both interactions increase in strength by the presence of the other interaction. As mentioned 
above, the non-H-bonded water proton is out of the plane of the halobenzene in the $\mathrm{H}$ bonded XPh- $\mathrm{H}_{2} \mathrm{O}$ structures, particularly for AtPh- $\mathrm{H}_{2} \mathrm{O}$ (out-of-plane angles of 17 and $54^{\circ}$ for I and At, respectively). In the IPh- $\left(\mathrm{H}_{2} \mathrm{O}\right)_{2}$ and AtPh- $\left(\mathrm{H}_{2} \mathrm{O}\right)_{2}$ structures the non-bonded water hydrogen has moved to being nearly in plane (out-of-plane angles of 3 and $10^{\circ}$ for I and At, respectively); thus there is a larger change, and therefore larger energy penalty, for AtPh$\left(\mathrm{H}_{2} \mathrm{O}\right)_{2}$. This correlates with the smaller increase in interaction energy due to cooperativity for this system.

\section{Comparison with $\mathrm{XmU}-\mathrm{H}_{2} \mathrm{O}$ and $\mathrm{XmU}-\left(\mathrm{H}_{2} \mathrm{O}\right)_{2}$}

The principal distinction between the $\mathrm{XmU}-\mathrm{H}_{2} \mathrm{O}$ and $\mathrm{XPh}-\mathrm{H}_{2} \mathrm{O}$ systems is that in the former there is a competing option of forming a strong $\mathrm{O} 4 \bullet \bullet \bullet \mathrm{H}_{\mathrm{w}} \mathrm{H}$-bond (cf. Figure 1). $\mathrm{ClmU}-\mathrm{H}_{2} \mathrm{O}$ did not form an X-bonded structure due to this competing interaction, which draws the water molecule away from the halogen towards the $\mathrm{C} 4=\mathrm{O} 4$ moiety. It turns out, however, that in $\mathrm{XPh}$ the neighbouring $\mathrm{C}-\mathrm{H}$ also acts as a competitor by trapping the water molecule through two unconventional $\mathrm{H}$-bonds $\left(\mathrm{CH} \bullet \bullet \mathrm{O}_{\mathrm{w}}\right.$ and $\left.\mathrm{O}_{\mathrm{w}} \mathrm{H}_{\mathrm{w}} \bullet \bullet \mathrm{X}\right)$. In doubly-hydrated $\mathrm{ClmU}$, when the $\mathrm{H}_{\mathrm{w}} \bullet \bullet \mathrm{O} 4$ hydrogen bond is obstructed, a $\mathrm{C} 5 \mathrm{Cl} \bullet \bullet \mathrm{H}_{\mathrm{w}}$ halogen bond does form, indicating that water can, in the absence of a competing interaction, form a halogen bond with a chlorine atom that is covalently bonded to an aromatic ring. However, a similar attempt to block the competing interaction in $\mathrm{ClPh}-\left(\mathrm{H}_{2} \mathrm{O}\right)_{2}$ did not produce an X-bond. There are several reasons for this: In the XmU- $\left(\mathrm{H}_{2} \mathrm{O}\right)_{2}$ structures, the two water molecules form a water dimer, which is bonded to XmU via both a $\mathrm{H}$-bond and X-bond. In XPh- $\left(\mathrm{H}_{2} \mathrm{O}\right)_{2}$ the two water molecules cannot form an X-bond while simultaneously forming a water dimer interacting with the benzene moiety. In ClPh- $\left(\mathrm{H}_{2} \mathrm{O}\right)_{2}$ the possibility of forming an X-bond is sacrificed for the more favourable water dimer located above the aromatic ring. The preference of water-dimer formation even prevents the formation of a $\mathrm{Br} \bullet \bullet \mathrm{O}_{w} \mathrm{X}$-bond in $\mathrm{BrPh}-\left(\mathrm{H}_{2} \mathrm{O}\right)_{2}$, even though such a halogen bond was found in the singly-hydrated species. The preference of forming a water dimer over separate interactions between the waters and the central molecule is consistent with previous work on microhydrated uracil, which showed that water molecules prefer to form two- and three-molecule water droplets binding to uracil, rather than distributing themselves over the different water-binding sites. ${ }^{[60]}$ A second reason for the presence of an $\mathrm{X}$-bonded $\mathrm{ClmU}-\left(\mathrm{H}_{2} \mathrm{O}\right)_{2}$ structure but absence of a corresponding $\mathrm{ClPh}-\left(\mathrm{H}_{2} \mathrm{O}\right)_{2}$ structure is the effect of the $\mathrm{O} 4$ atom in $\mathrm{XmU}$ on the electronic structure of the molecule by means of electron-withdrawing effects. Ketones are polar with electron density concentrated on the oxygen. Further electron-withdrawing effects could be induced by the carbonyl groups and nitrogen atoms in the ring. The combined electron-withdrawing effects presumably deplete the electron density in the ring of $\mathrm{XmU}$, thus increasing the electron deficiency in the $\sigma$-hole region on the halogen atom, and thereby rendering the halogen atom more capable of forming halogen bonds. This rationalisation is consistent with the greater magnitude of the interaction energy of the X-bonded $\mathrm{mXU}-\mathrm{H}_{2} \mathrm{O}$ structures compared to the X-bonded XPh- $\mathrm{H}_{2} \mathrm{O}$ structures (XPh- $\mathrm{H}_{2} \mathrm{O}:-7.3,-13.3$ and $-18.6 \mathrm{~kJ} / \mathrm{mol} ; \mathrm{mXU}-\mathrm{H}_{2} \mathrm{O}:-12.2,-18.6$ and -25.5 $\mathrm{kJ} / \mathrm{mol} ;{ }^{[26,35]}$ for $\mathrm{X}=\mathrm{Br}, \mathrm{I}, \mathrm{At}$, respectively). It is also consistent with the MEPs: for CImU there 
is a clear $\sigma$-hole visible in the MEP. ${ }^{[26]}$ For CIPh, however, the electrostatic potential at the extension of the $\mathrm{C}-\mathrm{Cl}$ bond is approximately neutral (Figure 2). In addition, the Wiberg bond indices are slightly larger in $\mathrm{XmU}-\mathrm{H}_{2} \mathrm{O}$ compared to $\mathrm{XPh}-\mathrm{H}_{2} \mathrm{O}$ : for the $\mathrm{X}$-bond in $\mathrm{XmU}-\mathrm{H}_{2} \mathrm{O}$ the bond indices are 00130, 0.0265 and 0.0313 for $X=B r, I$ and At, respectively, compared with $0.0098,0.00178$ and 0.0248 for the corresponding $\mathrm{XPh}-\mathrm{H}_{2} \mathrm{O}$ complexes (see above).

Thus, the combination of the greater electron deficiency of the $\sigma$-hole in $\mathrm{mClU}$ compared with $\mathrm{CIPh}$ and the possibility to form a water dimer and X-bond simultaneously when the $\mathrm{H}_{\mathrm{w}} \bullet \bullet \bullet \mathrm{O} 4$ hydrogen bond is obstructed (by the second water molecule) explain the formation of the Xbonded mClU-( $\left.\mathrm{H}_{2} \mathrm{O}\right)_{2}$ structure, but not a corresponding PhU-( $\left.\mathrm{H}_{2} \mathrm{O}\right)_{2}$ structure.

\section{Conclusions}

We find that all of the singly-hydrated halobenzene molecules form hydrogen bonds with the water molecule. The hydrogen-bonded structures form two unconventional $\mathrm{H}$-bonds $(\mathrm{CH}-$ $\bullet \bullet \mathrm{O}_{\mathrm{w}}$ and $\left.\mathrm{O}_{\mathrm{w}} \mathrm{H}_{\mathrm{w}} \bullet \bullet \mathrm{X}\right) . \mathrm{HX} \bullet \bullet \mathrm{O}_{\mathrm{w}}$ halogen bonding was found to occur in cases where the halogen atom is heavier than chlorine, with the magnitude of the interaction energy increasing going down the halogen group. There is also a trend going down the halogen group towards shorter $\mathrm{X} \bullet \bullet \mathrm{O}_{\mathrm{w}}$ internuclear distances. Astatobenzene is unique in forming a halogen bond that is stronger than all of the $\mathrm{X} \bullet \bullet \bullet \mathrm{H}_{\mathrm{w}}$ hydrogen bonds. In doubly-hydrated halobenzene, when the neighbouring $\mathrm{C}-\mathrm{H}$ is obstructed by a second water molecule, halogenbonded structures are formed only for halogens heavier than bromine. The doubly-hydrated halobenzenes with halogens lighter than iodine do not form halogen bonds due to propensity of the two water molecules to form a water dimer, which is not compatible with a halogen bond in the case of halobenzene. Thus, even in the absence of competing strong interactions with other functional groups in the parent molecule, halogen bonds may not form due to competition from cooperative weak interactions, for example in the case of $X \mathrm{Xh}-\mathrm{H}_{2} \mathrm{O}, \mathrm{a}$ combination of $\mathrm{CH}-\mathrm{O}$ and $\mathrm{OH}-\mathrm{X}$ hydrogen bonds. This study also shows that blocking the competing site with one water molecule while attempting to form a halogen bond between the parent molecule and a second water molecule may fail due to the propensity of water molecules to aggregate.

\section{Acknowledgements}

We thank EastCHEM for support via the EaStCHEM Research Computing Facility.

\section{Supporting Information}

Additional Supporting Information may be found in the online version of this article. 


\section{References}

[1] J. Černý; P. Hobza. Phys. Chem. Chem. Phys. 2007, 9, 5291-5303.

[2] M. Tafipolsky. J. phys. Chem. A 2016, 120, 4550-4559.

[3] B. Wang; W. Jiang; X. Dai; Y. Gao; Z. Wang; R.-Q. Zhang. Sci. Rep. 2016, 6, 22099.

[4] K. Müller-Dethlefs; P. Hobza. Chem. Rev. 2000, 100, 143-168.

[5] S. Bommarito; N. Peyret; J. S. Jr. Nucl. Acids Res. 2000, 28, 1929-1934.

[6] E. T. Kool. Annu. Rev. Biophys. Biomol. Struct. 2001, 30, 1-22.

[7] P. Yakovchuk; E. Protozanova; M. D. Frank-Kamenetskii. Nucleic Acids Res. 2006, 34, 564-

574.

[8] G. Stefan. Wiley Interdiscip. Rev. Comput. Mol. Sci. 2011, 1, 211-228.

[9] Y. Zhao; D. G. Truhlar. Theor. Chem. Acc. 2008, 120, 215-241.

[10] Y. Zhao; D. G. Truhlar. J. Phys. Chem. C 2008, 112, 4061-4067.

[11] Y. Zhao; D. G. Truhlar. Chem. Phys. Lett. 2011, 502, 1-13.

[12] J.-J. Colin. Ann. Chem. 1814, 91, 252-272.

[13] J. M. Dumas; H. Peurichard; M. Gomel. J. Chem. Res. (S) 1978, 54-55.

[14] A. J. Parker; J. Stewart; K. J. Donald; C. A. Parish. J. Am. Chem. Soc. 2012, 134, 5165-5172.

[15] K. E. Riley; C. L. Ford Jr; K. Demouchet. Chem. Phys. Lett. 2015, 621, 165-170.

[16] G. Cavallo; P. Metrangolo; R. Milani; T. Pilati; A. Priimagi; G. Resnati; G. Terraneo. Chem. Rev. 2016, 116, 2478-2601.

[17] A. C. Legon. Phys. Chem. Chem. Phys. 2010, 12, 7736-7747.

[18] P. Politzer; P. Lane; M. Concha; Y. Ma; J. Murray. J. Mol. Model. 2007, 13, 305-311.

[19] P. Politzer; J. S. Murray. ChemPhysChem 2013, 14, 278-294.

[20] R. Wilcken; M. O. Zimmermann; A. Lange; A. C. Joerger; F. M. Boeckler. J. Med. Chem. 2013, 56, 1363-1388.

[21] B. Antonio; F. Antonio. ChemPhysChem 2015, 16, 3108-3113.

[22] Y. Geboes; N. Nagels; B. Pinter; F. De Proft; W. A. Herrebout. J. Phys. Chem. A 2015, 119, 2502-2516.

[23] W. Tian; Q. Li. Int. J. Quant. Chem. 2015, 115, 99-105.

[24] M. D. Esrafili; S. Asadollahi; Y. Dadban Shahamat. Struct. Chem. 2016, 27, 1439-1447.

[25] F. Jindřich; H. Josef; R. Zdeňka; Ř. Jan; L. P. D.; W. D. A.; H. Drahomír; R. Aleš; H. Pavel. ChemPhysChem 2016, 17, 3373-3376.

[26] S. W. L. Hogan; T. van Mourik. J. Comput. Chem. 2016, 37, 763-770.

[27] Y. Xing; Z. Hongrui; Z. Yi. Int. J. Quant. Chem. 2016, 116, 1244-1253.

[28] P.-Y. Chen; L. Zhang; S.-G. Zhu; G.-B. Cheng. J. Mol. Struct. 2017, 1131, 250-257.

[29] Y. Geboes; F. De Proft; W. A. Herrebout. J. Phys. Chem. A 2017, 121, 4180-4188.

[30] Y. Geboes; F. De Proft; W. A. Herrebout. J. Mol. Struct. 2018, 1165, 349-355.

[31] N. Ramasubbu; R. Parthasarathy; P. Murray-Rust. J. Am. Chem. Soc. 1986, 108, 4308-4314.

[32] J. G. Hill; X. Hu. Chem. Eur. J. 2013, 19, 3620-3628.

[33] Z. Xu; Z. Yang; Y. Liu; Y. Lu; K. Chen; W. Zhu. J. Chem. Inf. Model. 2014, 54, 69-78.

[34] T. Clark; M. Hennemann; J. Murray; P. Politzer. J. Mol. Model. 2007, 13, 291-296.

[35] S. W. L. Hogan; T. van Mourik. J. Comput. Chem. 2017, 38, 933-933.

[36] F. Adasme-Carreno; C. Munoz-Gutierrez; J. H. Alzate-Morales. RSC Adv. 2016, 6, 6183761847.

[37] L. Muzangwa; S. Nyambo; B. Uhler; S. A. Reid. J. Chem. Phys. 2012, 137, 184307.

[38] S. A. Reid; S. Nyambo; L. Muzangwa; B. Uhler. J. Phys. Chem. A 2013, 117, 13556-13563.

[39] Y. Zhang; B. Ji; A. Tian; W. Wang. J. Chem. Phys. 2012, 136, 141101.

[40] D. Sutradhar; A. K. Chandra. Int. J. Quant. Chem. 2018, 118, e25511.

[41] K. El Hage; J.-P. Piquemal; Z. Hobaika; R. G. Maroun; N. Gresh. Chem. Phys. Lett. 2015, 637, 51-57.

[42] E. H. Krystel; P. Jean-Philip; H. Zeina; M. R. G.; G. Nohad. J. Comput. Chem. 2015, 36, 210-

221. 
[43] A. Frisch; A. B. Nielson; A. J. Holder. Gaussian Inc., Pittsburgh, PA 2000.

[44] Y. Zhao; D. G. Truhlar. Journal of Chemical Physics 2006, 125.

[45] M. J. Frisch; G. W. Trucks; H. B. Schlegel; G. E. Scuseria; M. A. Robb; J. R. Cheeseman; G.

Scalmani; V. Barone; B. Mennucci; G. A. Petersson; H. Nakatsuji; M. Caricato; X. Li; H. P. Hratchian; A. F. Izmaylov; J. Bloino; G. Zheng; J. L. Sonnenberg; M. Hada; M. Ehara; K. Toyota; R. Fukuda; J.

Hasegawa; M. Ishida; T. Nakajima; Y. Honda; O. Kitao; H. Nakai; T. Vreven; J. Montgomery, J. A.; J. E. Peralta; F. Ogliaro; M. Bearpark; J. J. Heyd; E. Brothers; K. N. Kudin; V. N. Staroverov; R. Kobayashi; J. Normand; K. Raghavachari; A. Rendell; J. C. Burant; S. S. Iyengar; J. Tomasi; M. Cossi; N. Rega; N. J. Millam; M. Klene; J. E. Knox; J. B. Cross; V. Bakken; C. Adamo; J. Jaramillo; R. Gomperts; R. E.

Stratmann; O. Yazyev; A. J. Austin; R. Cammi; C. Pomelli; J. W. Ochterski; R. L. Martin; K. Morokuma; V. G. Zakrzewski; G. A. Voth; P. Salvador; J. J. Dannenberg; S. Dapprich; A. D. Daniels; Ö. Farkas; J. B. Foresman; J. V. Ortiz; J. Cioslowski; D. J. Fox, Gaussian 09, Rev. A.02, Wallingford CT, 2009.

[46] K. A. Peterson; D. Figgen; E. Goll; H. Stoll; M. Dolg. Journal of Chemical Physics 2003, 119, 11113-11123.

[47] S. Kozuch; J. M. L. Martin. J. Chem. Theor. Comput. 2013, 9, 1918-1931.

[48] R. S. Hunter; T. van Mourik. J. Comput. Chem. 2012, 33, 2161-2172.

[49] S. F. Boys; F. Bernardi. Molecular Physics 1970, 19, 553-\&.

[50] S. E. Wheeler; K. N. Houk. Journal of Chemical Theory and Computation 2010, 6, 395-404.

[51] I. D. Mackie; G. A. DiLabio. Phys. Chem. Chem. Phys. 2010, 12, 6092-6098.

[52] K. B. Wiberg. Tetrahedron 1968, 24, 1083-1096.

[53] P. Auffinger; F. A. Hays; E. Westhof; P. S. Ho. Proc. Natl. Acad. Sci. USA 2004, 101, 1678916794.

[54] W. Li; Y. Zeng; X. Li; Z. Sun; L. Meng. J. Comput. Chem. 2015, 36, 1349-1358.

[55] N. Nagels; Y. Geboes; B. Pinter; F. De Proft; W. A. Herrebout. Chem. Eur. J. 2014, 20, 84338443.

[56] M. R. Scholfield; M. C. Ford; C. M. Vander Zanden; M. M. Billman; P. S. Ho; A. K. Rappé. J. Phys. Chem. B 2015, 119, 9140-9149.

[57] A. Varadwaj; P. R. Varadwaj; B.-Y. Jin. Int. J. Quant. Chem. 2015, 115, 453-470.

[58] Y. Wang; J. Tong; W. Wu; Z. Xu; Y. Lu. Int. J. Quant. Chem. 2015, 115, 884-890.

[59] A. Kovács; Z. Varga. Coord. Chem. Rev. 2006, 250, 710-727.

[60] T. van Mourik. Phys. Chem. Chem. Phys. 2001, 3, 2886-2892.

[61] Http://Www.Rsc.Org/Periodic-Table/Element/85/Astatine. Accessed: 11 March 2015.

[62] Crc Handbook of Chemistry and Physics; Lide, D. R. (Ed.); 90th ed.; CRC Press: Boca Raton (Fla, USA), 2009.

[63] T. Clark; M. Hennemann; J. S. Murray; P. Politzer. Journal of Molecular Modeling 2007, 13, 291-296. 


\section{GRAPHICAL ABSTRACT}

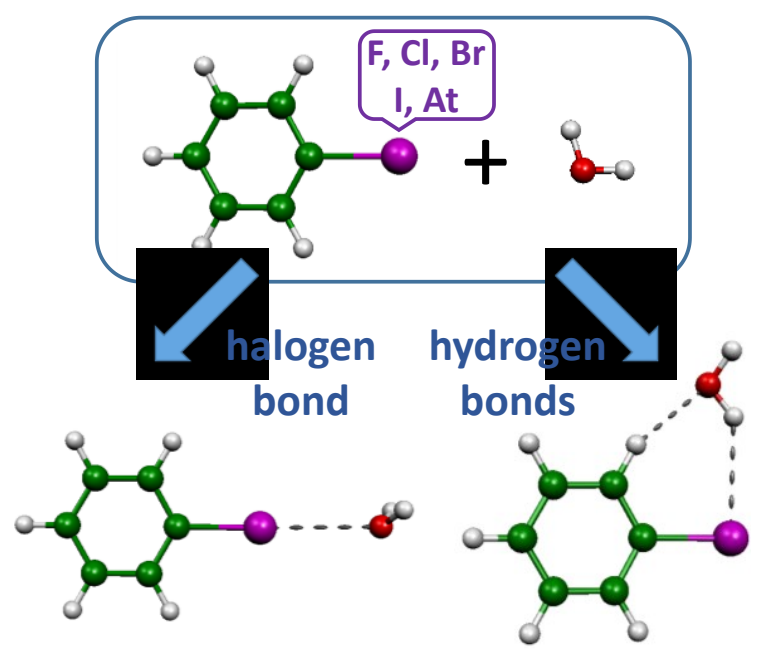

Even in the absence of other functional groups, halogen bonds face competition from hydrogen bonds 